\title{
Enhancement of Quality in Power Systems With Active Power Filters
}

\author{
Vikash Anand $^{1}$, Dr. S. K. Srivastava ${ }^{2}$ \\ ${ }^{1}$ PhD Student, Electrical Engineering, NIT-Patna, Bihar, India \\ ${ }^{2}$ Associate Professor, Electrical Engineering, MMMTU-Gorakhpur, Uttar Pradesh, India
}

\begin{abstract}
The study of hysteresis current controlled three phase active power filters to improve power quality by compensating harmonics and reactive power required by a non-linear load is presented. The shunt active filter employs a simple method for the reference compensation current based on Fast Fourier Transform. The series active filter employs a simple method for the reference compensation voltage based on $p-q$ theory. UPQC consists of back to back connected series and shunt active filters, and is modeled with reference to a synchronously rotating d-q-o reference axes. The shunt active power filter compensates the source current harmonics and also it maintains the dc link voltage unchanged in steady state, while the series active power filter compensates the load voltage harmonics. Classic filters may not have satisfactory performance in fast varying conditions. But auto tuned active power filters give better results for harmonics minimization, reactive power compensation and power factor improvement. This paper has proposed an auto tuned active filter, which maintains the THD well within the IEEE-519 standards.
\end{abstract}

Key Words: Power system, Active power filters, PI Controller, Hysteresis Current Pulse Width Modulation.

\section{INTRODUCTION}

The present power distribution system is usually configured as a three-phase three-wire or four-wire structure featuring a power-limit voltage source with significant source impedance, and an aggregation of various types of loads. Ideally, the system should provide a balanced and pure sinusoidal three-phase voltage of constant amplitude to the loads; and the loads should draw a current from the line with unity power factor, zero harmonics, and balanced phases. To four-wire systems, no excessive neutral current should exist. As a result, the maximum power capacity and efficiency of the energy delivery are achieved, minimum perturbation to other appliances is ensured, and safe operation is warranted. However, with a fast increasing number of applications of industry electronics connected to the distribution systems today, including nonlinear, switching, reactive, single-phase and unbalanced three-phase load, a complex problem of power quality evolved characterized by the voltage and current harmonics, unbalances, low power factor. [1]

In recent years active methods for power quality control have become more attractive compared with passive ones due to their fast response, smaller size, and higher performance. For example, Static VAR Compensator (SVC) have been reported to improve the power factor; Power Factor Corrector (PFC) and Active Power Filters (APF) have the ability of current harmonics suppression and power factor correction; some active circuits were developed to compensate unbalanced currents as well as limit the neutral current. In general, parallel-connected converters have the ability to improve the current quality while the series-connected regulators inserted between the load and the supply, improve the voltage quality. For voltage and current quality control, both series and shunt converters are necessary, which is known as Unified Power Quality Conditioner (UPQC) and have been analyzed in this thesis. UPQC was presented during 1998. Such solution can compensate for different power quality phenomena, such as: sags, swells, voltage imbalance, flicker, harmonics and reactive currents. [7]

There are several current control strategies proposed in the literature, namely, PI control, Average Current Mode Control (ACMC), Sliding Mode Control (SMC) and hysteresis control. Among the various current control techniques, hysteresis control is the most popular one for active power filter applications. Hysteresis current control is a method of controlling a voltage source inverter so that the output current is generated which follows a reference current waveform. $[2,11]$

This paper basically deals with the modeling and design of active power filters for compensation of harmonics and reactive power. Designs of different parameters like power circuit, thyristor controlled capacitor banks; series active filter, shunt active filter, UPQC are discussed.

\section{SHUNT ACTIVE POWER FILTER (SHUNT APF)}

The shunt active power filter, with a self controlled dc bus, has a topology similar to that of a static compensator (STATCOM) used for reactive power compensation in power transmission systems. Shunt active 
power filters compensate load current harmonics by injecting equal but opposite harmonic compensating current. In this case the shunt active power filter operates as a current source injecting the harmonic components generated by the load but phase shifted by $180^{\circ}$. Fig. 1 shows the three leg topology of shunt active filter. Fig. 2 shows how active power filter works to compensate the load harmonic currents and Fig. 3 shows the connection of a shunt active power filter. [2, 7, 9]

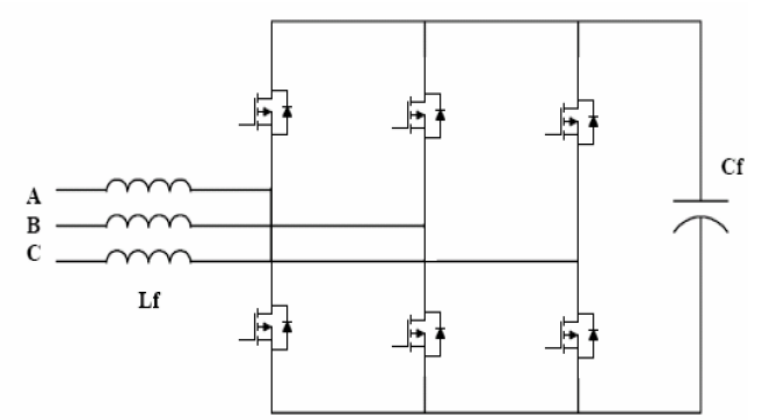

Fig.1 Three leg topology of shunt active power filter

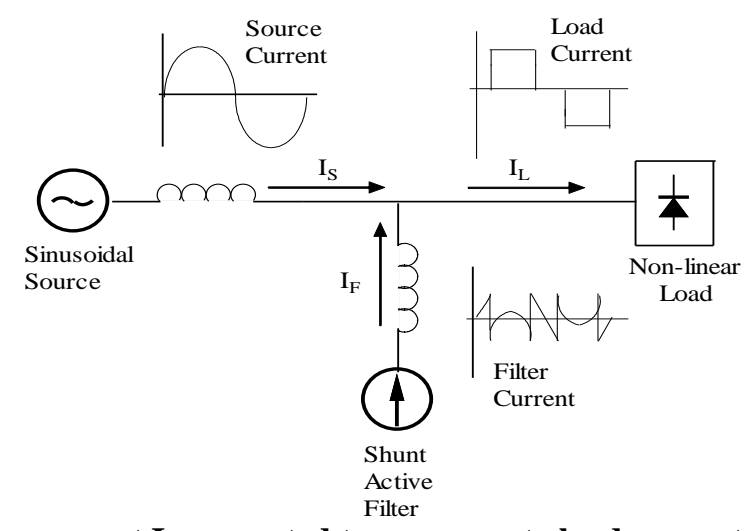

Fig.2 Filter current $I_{F}$ generated to compensate load current harmonics

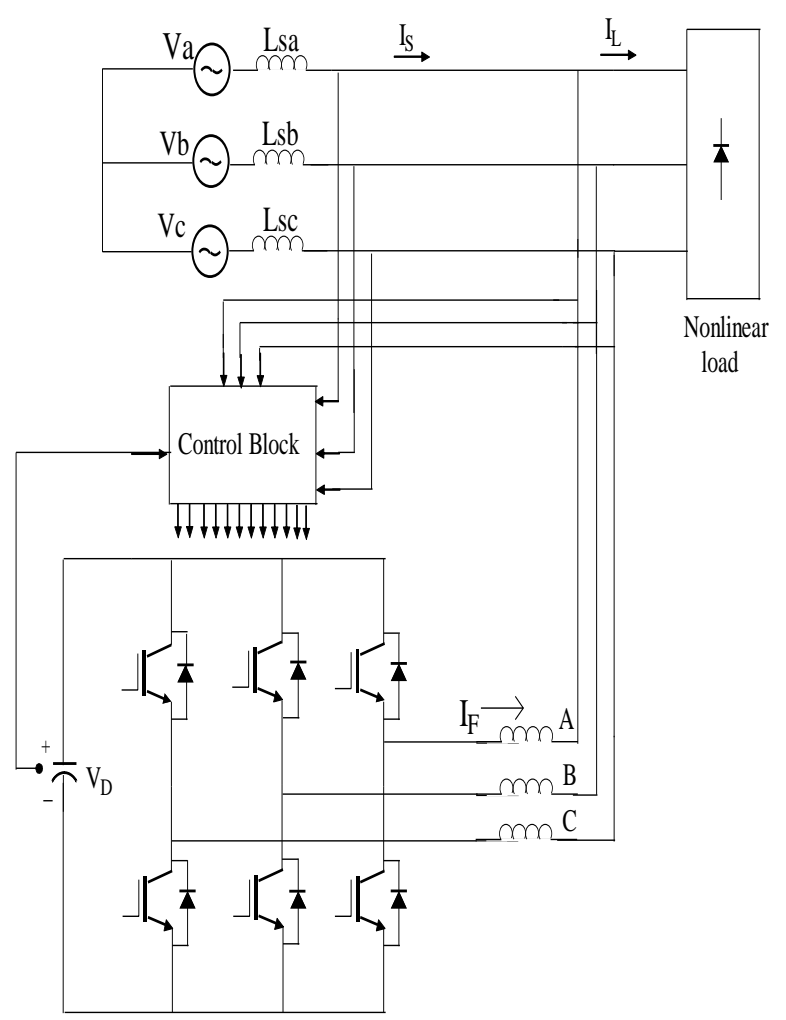

Fig.3 Shunt active power filter topology 


\subsection{Basic Compensation Principle}

Fig.4 shows the basic compensation principle of shunt active power filter. A voltage source inverter (VSI) is used as the shunt active power filter. This is controlled so as to draw or supply a compensating current $I_{c}$ from or to the utility, such that it cancels current harmonics on the AC side i.e. this active power filter (APF) generates the nonlinearities opposite to the load nonlinearities [3].

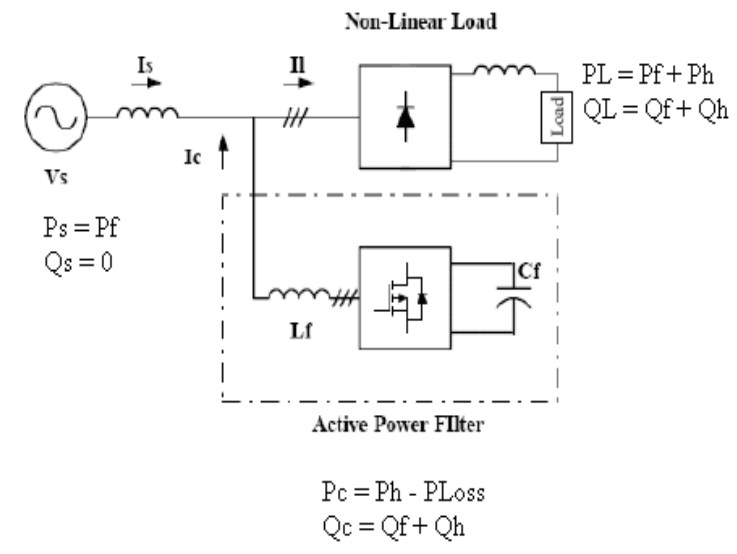

Fig.4 Single line diagram of the shunt active power filter showing power flow

Total instantaneous power drawn by the nonlinear load can be represented as:-

$\mathrm{p}_{\mathrm{L}}(\mathrm{t})=\mathrm{p}_{\mathrm{f}}(t)+\mathrm{p}_{\mathrm{r}}(t)+\mathrm{p}_{\mathrm{h}}(t)$

Where,

$\mathrm{p}_{\mathrm{f}}(\mathrm{t})$ - instantaneous fundamental (real) power absorbed by the load,

$\mathrm{p}_{\mathrm{r}}(\mathrm{t})$ - instantaneous reactive power drawn by the load, and

$\mathrm{p}_{\mathrm{h}}(\mathrm{t})$ - instantaneous harmonic power drawn by the load.

In order to achieve unity power factor operation and drawing sinusoidal currents from the utility, active power filter must supply all the reactive and harmonics power demand of the load. At the same time, active filter will draw real component of power $\left(\mathrm{P}_{\text {Loss }}\right)$ from the utility, to supply switching losses and to maintain the DC link voltage unchanged.

Power components (reactive and the harmonic) should be supplied by the active power filters i.e.

$$
\mathrm{p}_{\mathrm{c}}(t)=\mathrm{p}_{\mathrm{r}}(t)+\mathrm{p}_{\mathrm{h}}(t)
$$

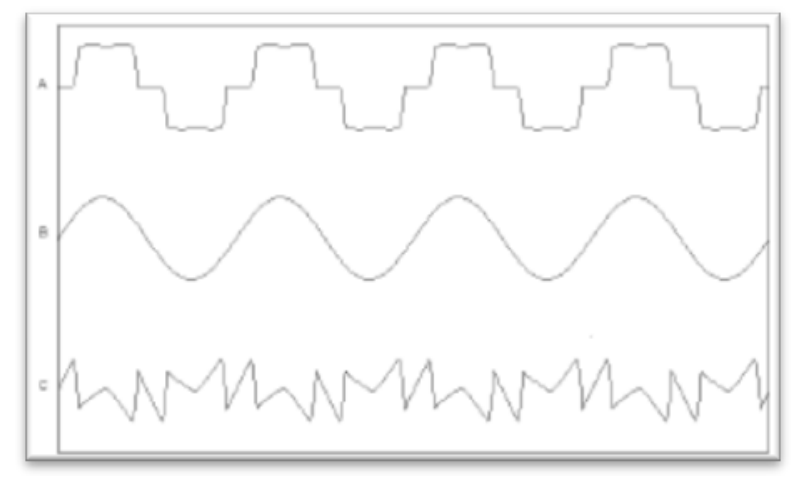

Fig.5 Waveform for Actual Load Current (A)

Desired Source Current (B) and

The Compensating Filter Current (C).

\subsection{Estimation of Reference Source Current}

From the single line diagram shown in fig.2

$\mathrm{i}_{\mathrm{s}}(\mathrm{t})=\mathrm{i}_{\mathrm{L}}(\mathrm{t})-\mathrm{i}_{\mathrm{c}}(\mathrm{t})$

Where,

$i_{s}(t), i_{L}(t), i_{c}(t)$ are the instantaneous value of source current, load current and the filter current. 
And the utility voltage is given by

$\mathrm{v}_{\mathrm{s}}(\mathrm{t})=\mathrm{V}_{\mathrm{m}} \sin \omega \mathrm{t}$

Where,

$\mathrm{v}_{\mathrm{s}}(\mathrm{t})$ - is the instantaneous value of the source voltage,

$\mathrm{V}_{\mathrm{m}}$ - is the peak value of the source voltage.

If non-linear load is connected then the load current will have a fundamental component and the harmonic

components which can be represented as -

$$
\mathrm{i}_{\mathrm{L}}(\mathrm{t})=\sum_{\mathrm{n}=1}^{\infty} \mathrm{I}_{\mathrm{n}} \sin \left(\mathrm{n} \omega \mathrm{t}+\phi_{\mathrm{n}}\right)
$$

$$
\mathrm{I}_{1} \sin \left(\omega \mathrm{t}+\phi_{1}\right)+\sum_{\mathrm{n}=2}^{\infty} \mathrm{I}_{\mathrm{n}} \sin \left(\mathrm{n} \omega \mathrm{t}+\phi_{\mathrm{n}}\right)
$$

$\bar{W}$ here, $I_{1}$ and $\phi_{1}$ are the amplitude of the fundamental current and its angle with respect to the fundamental voltage, and

$\mathrm{I}_{\mathrm{n}}$ and $\phi_{\mathrm{n}}$ are the amplitude of the nth harmonic current and its angle.

Instantaneous load power $\mathrm{p}_{\mathrm{L}}(\mathrm{t})$ can be expressed as-

$\mathrm{p}_{\mathrm{L}}(\mathrm{t})=\mathrm{V}_{\mathrm{s}}(\mathrm{t}) \mathrm{i}_{\mathrm{L}}(\mathrm{t})$

$=\mathrm{V}_{\mathrm{m}} \sin \omega \mathrm{t} \mathrm{I}_{1} \sin \left(\omega \mathrm{t}+\phi_{1}\right)+$

$\mathrm{V}_{\mathrm{m}} \sin \omega \mathrm{t} \sum_{\mathrm{n}=2}^{\infty} \mathrm{I}_{\mathrm{n}} \sin \left(\mathrm{n} \omega \mathrm{t}+\phi_{\mathrm{n}}\right)$

$=\mathrm{p}_{\mathrm{f}}(t)+\mathrm{p}_{\mathrm{r}}(t)+\mathrm{p}_{\mathrm{h}}(t)$

$=\mathrm{p}_{\mathrm{f}}(t)+\mathrm{p}_{\mathrm{c}}(t)$

In the equation (4) and (5)

$\mathrm{p}_{\mathrm{f}}(t)$ is the real power (fundamental),

$\mathrm{p}_{\mathrm{r}}(t)$ represents the reactive power and

$\mathrm{p}_{\mathrm{h}}(t)$ represents the harmonic power drawn by the load.

For ideal compensation only the real power (fundamental) should by supplied by the source while all other power components (reactive and the harmonic) should be supplied by the active power filters i.e. $\mathrm{p}_{\mathrm{c}}(t)=$ $\mathrm{p}_{\mathrm{r}}(t)+\mathrm{p}_{\mathrm{h}}(t)$

The total peak current supplied by the source

$\mathrm{I}_{\max }=\mathrm{I}_{\mathrm{sm}}+\mathrm{I}_{\mathrm{sL}}$

Where, $\mathrm{I}_{\mathrm{sm}}=\mathrm{I}_{1} \cos \phi_{1}$

and $I_{s L}$ is the loss component of current drawn from the source.

If active power filter provide the total reactive and harmonic power, then $i_{s}(t)$ will be in phase with the utility and pure sinusoidal. At this time, the active filter must provide the following compensation current:

$\mathrm{I}_{\mathrm{c}}(\mathrm{t})=\mathrm{I}_{\mathrm{L}}(\mathrm{t})-\mathrm{i}_{\mathrm{s}}(\mathrm{t})$

Hence, for the accurate and instantaneous compensation of reactive and harmonic power it is very necessary to calculate the accurate value of the instantaneous current supplied by the source.

$$
\mathrm{I}_{\mathrm{s}}(\mathrm{t})=\mathrm{I}_{\max } \sin \omega \mathrm{t}
$$

Where, $I_{\max }\left(=I_{1} \cos \phi_{1}+I_{s L}\right)$ is the amplitude of the desired source currents. The phase angles can be obtained from the source voltages. Hence, the waveform and phases of the source currents are known and only the magnitude of the source currents needs to be determined.

The peak value or the reference current $I_{\max }$ is estimated by regulating the DC link voltage of the inverter. This DC link voltage is compared by a reference value and the error is processed in a PI controller. The output of the 
PI controller is considered as the amplitude of the desired source currents and the reference currents are estimated by multiplying this peak value with the unit sine vectors in phase with the source voltages.

\section{SERIES ACTIVE POWER FILTER (SERIES APF)}

Series active power filters operate mainly as a voltage regulator and as a harmonic isolator between the nonlinear load and the utility system. The series connected filter protects the consumer from an inadequate supply voltage quality. This type of approach is especially recommended for compensation of voltage unbalances and voltage sags from the ac supply and for low power applications and represents economically attractive alternatives to UPS, since no energy storage (battery) is necessary and the overall rating of the components is smaller. The series active filter injects a voltage component in series with the supply voltage and therefore can be regarded as a controlled voltage source, compensating voltage sags and swells on the load side. In many cases, the series active filters work as hybrid topologies with passive LC filters. If passive LC filters are connected in parallel to the load, the series active power filter operates as a harmonic isolator, forcing the load current harmonics to circulate mainly through the passive filter rather than the power distribution system. $[3,4$, $7,9]$

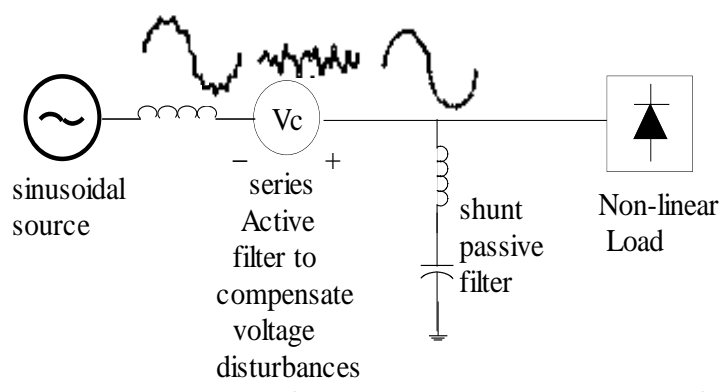

Fig.6 Filter voltage generation to compensate voltage disturbances

Fig.6 shows how the series active filter works to compensate the voltage harmonics on the load side and Fig.7 shows the connection of a series active power filter.

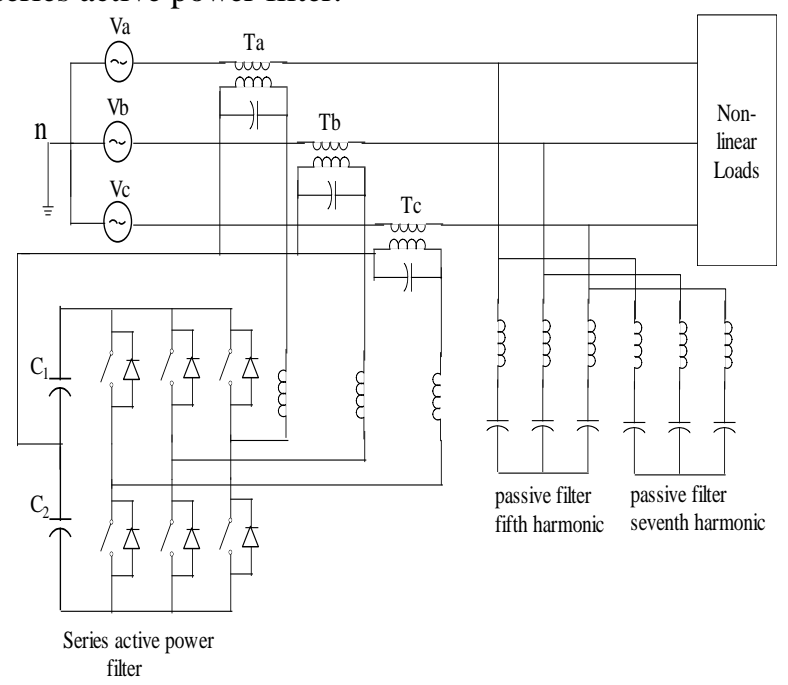

Fig. 7 Series active power filter topology with shunt passive filters

\subsection{Basic Compensation Principle}

Fig. 8 shows the basic compensation principle of series active power filter. A voltage source inverter (VSI) is used as the series active power filter. This is controlled so as to draw or inject a compensating voltage $\mathrm{V}_{\mathrm{c}}$ from or to the supply, such that it cancels voltage harmonics on the load side i.e. this active power filter (APF) generates the distortions opposite to the supply harmonics [4].

Fig.9 shows the different waveforms i.e. source voltage, desired load voltage and the compensating voltage injected by the series active power filter which contains all the harmonics, to make the load voltage purely sinusoidal. This is the basic principle of series active power filter to eliminate the supply voltage harmonics. 


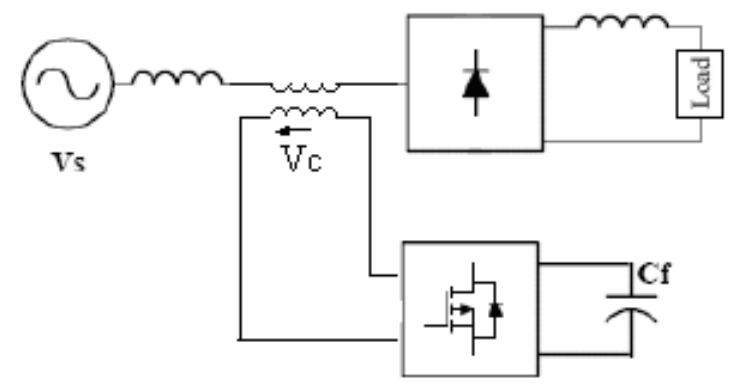

Fig.8 Basic compensation principle of series active power filter

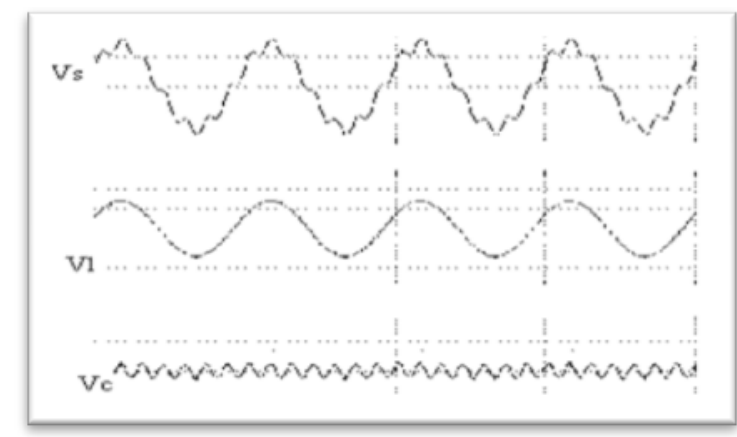

Fig.9 Waveforms for the Supply Voltage (Vs)

Desired Load Voltage (Vl), and

The Compensating Voltage (Filter Voltage- Vc)

\subsection{Estimation of Reference Voltage}

This Section introduces the control algorithm of the series active power filter, which compensates for harmonics and reactive power. The three-phase voltages $v_{a}, v_{b}$ and $v_{c}$ and currents $i_{a}, i_{b}$ and $i_{c}$ for the three-phase three-wire power distribution system is shown in Fig.10[11]-[10]-[4].

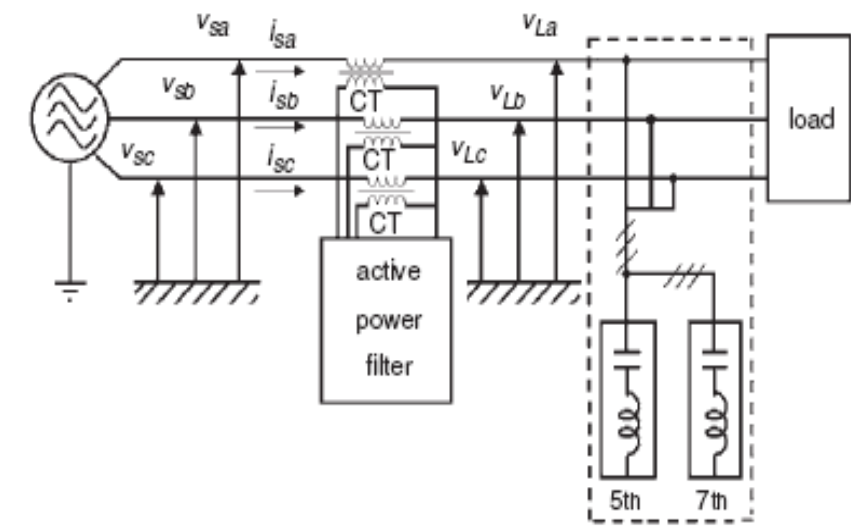

Fig.10 Circuit configuration for series active power filter

The three-phase load voltages $\mathrm{v}_{\mathrm{L}(\mathrm{a}, \mathrm{b}, \mathrm{c})}$ and the three-phase source currents $\mathrm{i}_{\mathrm{s}(\mathrm{a}, \mathrm{b}, \mathrm{c})}$ are represented as:

$V L(a, b, c)=\left[\begin{array}{c}V L a \\ V L b \\ V L c\end{array}\right], i_{s(a, b, c)}=\left[\begin{array}{c}i_{s a} \\ i_{s b} \\ i_{s c}\end{array}\right]$

The load voltage vector $\mathrm{VL}_{(\mathrm{a}, \mathrm{b}, \mathrm{c})}$ and the source current vector $\mathrm{i}_{\mathrm{s}(\mathrm{a}, \mathrm{b}, \mathrm{c})}$ of (1) are transformed into $\alpha \beta 0$ coordinates by the substituting (3) into (2) as 


$$
\begin{aligned}
& \mathrm{VL}_{(\alpha, \beta, 0)}=[\mathrm{T}]\left[\begin{array}{c}
\mathrm{V}_{\mathrm{La}} \\
\mathrm{V}_{\mathrm{Lb}} \\
\mathrm{V}_{\mathrm{Lc}}
\end{array}\right]=\left[\begin{array}{c}
\mathrm{q}_{\mathrm{L} \alpha} \\
\mathrm{q}_{\mathrm{L} \beta} \\
\mathrm{q}_{\mathrm{L} 0}
\end{array}\right] \\
& \mathrm{i}_{\mathrm{s}(\alpha, \beta, 0)}=[\mathrm{T}]\left[\begin{array}{c}
\mathrm{i}_{\mathrm{sa}} \\
\mathrm{i}_{\mathrm{sb}} \\
\mathrm{i}_{\mathrm{sc}}
\end{array}\right]=\left[\begin{array}{c}
\mathrm{i}_{\mathrm{s} \alpha} \\
\mathrm{i}_{s \beta} \\
\mathrm{i}_{\mathrm{s} 0}
\end{array}\right]
\end{aligned}
$$

Where,

$$
[\mathrm{T}]=\sqrt{\frac{2}{3}}\left[\begin{array}{ccc}
1 & -1 / 2 & -1 / 2 \\
0 & \sqrt{3} / 2 & -\sqrt{3} / 2 \\
1 / \sqrt{2} & 1 / \sqrt{2} & 1 / \sqrt{2}
\end{array}\right]
$$

The active power p can be expressed as (4) by the inner product of the load voltage vector $V L(\alpha, \beta, 0)$ and the source current vector $i_{s(\alpha, \beta, 0)}$ of (2), where the active power $p$ is the instantaneous active power at the load side of the CT in Fig. 10.

$$
\mathrm{p}=\mathrm{VL}(\alpha, \beta, 0) \mathrm{i}_{\mathrm{s}(\alpha, \beta, 0)}=\mathrm{VL}_{\mathrm{L} \alpha} \mathbf{i}_{\mathrm{s} \alpha}+\mathrm{VL}_{\mathrm{L}} \mathrm{i}_{\mathrm{s}} \beta+\mathrm{VL}_{\mathrm{L}} \mathrm{i}_{\mathrm{s} 0}
$$

Also, the reactive power $\mathrm{q}_{\mathrm{L}(\alpha, \beta, 0)}$ is represented as (5) by the cross product of $\mathrm{VL}_{\mathrm{L}(\alpha, \beta, 0)}$ and $\mathbf{i}_{\mathrm{s}}(\alpha, \beta, 0)$

$$
\mathrm{qL}_{(\alpha, \beta, 0)}=\mathbf{V L}(\alpha, \beta, 0) \times \mathbf{i}_{\mathbf{s}(\alpha, \beta, 0)}
$$

$q=\left\|q_{L(\alpha, \beta, 0)}\right\|=\left\|\mathrm{VL}(\alpha, \beta, 0) \times \mathrm{i}_{\mathrm{s}(\alpha, \beta, 0)}\right\|$

Where, $\mathrm{q}$ is the instantaneous reactive power at the load side of the CT in Fig.10.

For a three-phase system without zero sequence voltage and current, i.e.

$$
\begin{aligned}
& \mathrm{V}_{\mathrm{a}}+\mathrm{V}_{\mathrm{b}}+\mathrm{V}_{\mathrm{c}}=0 \text { And } \mathrm{i}_{\mathrm{a}}+\mathrm{i}_{\mathrm{b}}+\mathrm{i}_{\mathrm{c}}=0 \\
& \mathrm{~V}_{\mathrm{L} 0}=\frac{1}{3}\left(\mathrm{~V}_{\mathrm{a}}+\mathrm{V}_{\mathrm{b}}+\mathrm{V}_{\mathrm{c}}\right)=0 \quad \mathrm{i}_{\mathrm{s} 0}=\frac{1}{3}\left(\mathrm{i}_{\mathrm{a}}+\mathrm{i}_{\mathrm{b}}+\mathrm{i}_{\mathrm{c}}\right)=0,
\end{aligned}
$$

Equ. (4) and (5) can be expressed as follows:

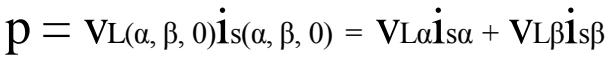

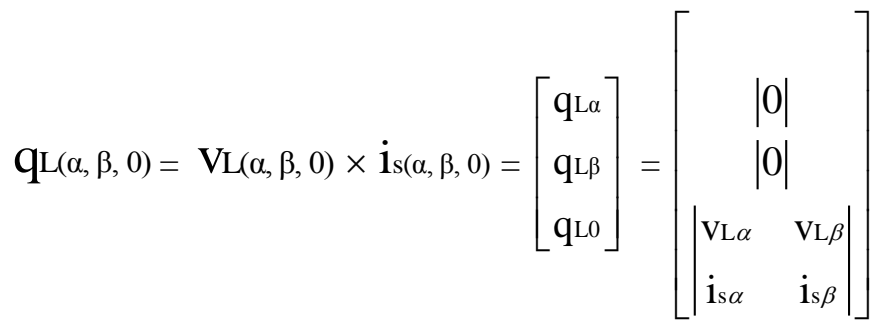

From (1)-(5), the active voltage vector $\mathbf{V}_{\mathbf{p}(\alpha, \beta, 0)}$ and the reactive voltage vector $\mathbf{V}_{\mathbf{q}(\alpha, \beta, 0)}$ are defined as follows:

$$
\begin{aligned}
& \mathrm{V}_{\mathrm{p}(\alpha, \beta, 0)}=\frac{\mathrm{p}}{\mathbf{i}_{(\alpha, \beta, 0)} \cdot \mathbf{i}_{(\alpha, \beta, 0)}} \mathbf{i}_{(\alpha, \beta, 0)} \\
& \mathrm{Vq}_{\mathrm{q}(\alpha, \beta, 0)}=\frac{\mathbf{q}(\alpha, \beta, 0) \times \mathbf{i}_{(\alpha, \beta, 0)}}{\mathbf{i}_{(\alpha, \beta, 0)} \mathbf{i}_{(\alpha, \beta, 0)}}
\end{aligned}
$$


The $V_{p}(\alpha, \beta, 0)$ represents the parallel component of the load voltage vector $\operatorname{VL}(\alpha, \beta, 0)$ to the current vector $\dot{i}_{\mathrm{s}(\alpha, \beta, 0)}$; $\mathrm{Vq}(\alpha, \beta, 0)$ represents the perpendicular component of the load voltage vector $\mathrm{VL}(\alpha, \beta, 0)$ to the current vector $i_{s}(\alpha, \beta, 0)$. As a result, the load voltage vector is represented by the sum of the active voltage vector $\mathrm{V}(\alpha, \beta, 0)$ and the reactive voltage vector $\mathrm{Vq}_{\mathrm{q}}(\alpha, \beta, 0)$ as follows:

$\mathrm{VL}(\alpha, \beta, 0)=\mathrm{Vp}(\alpha, \beta, 0)+\mathrm{Vq}(\alpha, \beta, 0)$

The active voltage vector $\operatorname{Vp}(\alpha, \beta, 0)$ is induced as follows, using the projection of the load voltage vector $\operatorname{VL}(\alpha, \beta, 0)$ onto the current vector $\mathbf{i}_{\mathbf{s}}(\alpha, \beta, 0)$ :

$\mathrm{V}_{\mathrm{p}(\alpha, \beta, 0)}=\operatorname{projiVL}_{\mathrm{V}(\alpha, \beta, 0)}=\frac{\mathrm{VL}(\alpha, \beta, 0) \mathrm{i}_{\mathrm{s}(\alpha, \beta, 0)}}{\left\|\mathrm{i}_{\mathrm{s}(\alpha, \beta, \beta, 0)}\right\|^{2}}$

The reactive voltage vector $\mathrm{V}_{\mathrm{q}}(\alpha, \beta, 0)$, which is perpendicular to the active voltage vector $\mathrm{V}_{\mathrm{p}}(\alpha, \beta, 0)$, is also induced through (13)-(16):

$\mathrm{qL}_{\mathrm{L}(\alpha, \beta, 0)}=\mathrm{VL}(\alpha, \beta, 0) \times \mathrm{i}_{\mathrm{s}(\alpha, \beta, 0)}$
$\mathrm{i}_{\mathrm{s}(\alpha, \beta, 0)} \times \mathrm{qL}_{\mathrm{L}(\alpha, \beta, 0)}=\mathrm{i}_{\mathrm{s}(\alpha, \beta, 0)} \times\left(\mathrm{VL}_{(\alpha, \beta, 0)} \times \mathrm{i}_{\mathrm{s}(\alpha, \beta, 0)}(13) \mathrm{VL}(\alpha, \beta, 0)=\frac{\mathrm{i}_{\mathrm{s}(\alpha, \beta, 0)} \times \mathrm{qL}(\alpha, \beta, 0)}{\| \mathrm{i}_{\mathrm{s}(\alpha, \beta, 0) \|^{2}}}+\frac{\mathrm{p}}{\| \mathrm{i}_{\mathrm{s}(\alpha, \beta, 0) \|^{2}}} \mathrm{i}_{\mathrm{s}(\alpha, \beta, 0)}\right.$

The second term of the right-hand side of (15) is the active voltage vector $V_{p}(\alpha, \beta, 0)$ and the first term of the righthand side of (14) becomes the reactive voltage vector $\operatorname{Vq}(\alpha, \beta, 0)$ :

$\mathrm{V}_{\mathrm{q}(\alpha, \beta, 0)}=\frac{\mathrm{i}_{\mathrm{s}(\alpha, \beta, 0)} \times \mathrm{qL}_{\mathrm{L}(\alpha, \beta, 0)}}{\left\|\mathrm{i}_{\mathrm{s}(\alpha, \beta, 0)}\right\|^{2}}=\frac{\mathrm{i}_{\mathrm{s}(\alpha, \beta, 0)} \times \mathrm{qL}_{\mathrm{L}(\alpha, \beta, 0)}}{\mathrm{i}_{\mathrm{s}(\alpha, \beta, 0) \mathrm{i}_{(\alpha, \beta, 0)}}}$

Where $\mathrm{q}_{\mathrm{L}(\alpha, \beta, 0)}$ is equal to the reactive power, which is defined in the instantaneous reactive power theory. The voltage compensation reference of the series active power filter can be represented as (16), using $\operatorname{Vp}(\alpha, \beta, 0)$ and $\mathrm{Vq}(\alpha, \beta, 0)$ in (9) and (10):

$\mathrm{v}_{\mathrm{C}(\alpha, \beta, 0)}^{*}=\frac{\tilde{\rho}}{\mathrm{i}_{\mathrm{s}(\alpha, \beta, 0) \mathrm{i}_{\mathrm{s}(\alpha, \beta, 0)}}} \mathrm{i}_{\mathrm{s}(\alpha, \beta, 0)}+\frac{\mathrm{i}_{\mathrm{s}(\alpha, \beta, 0)} \times \mathrm{qL}_{\mathrm{L}(\alpha, \beta, 0)}}{\mathrm{i}_{\mathrm{s}(\alpha, \beta, 0) \mathrm{i}_{\mathrm{s}(\alpha, \beta, 0)}}}$

The active power and the reactive power can be divided into DC components $\widetilde{\mathrm{p}}$ and $\widetilde{\mathrm{q}}$, which are generated from the fundamental components of the load voltages and the source currents, and AC components $\widetilde{p}$ and $\widetilde{q}$, which are generated from the negative sequence components and the harmonic components of the load voltages and the source currents. If the reactive power $\mathrm{q}$ is replaced by the $\mathrm{AC}$ component of reactive power $\widetilde{q}$, a new voltage compensation reference compensates for the AC component of the active power $\widetilde{p}$ and the reactive power $\widetilde{\mathrm{q}}$.

The compensation voltage reference in $\alpha \beta 0$ co-ordinates is obtained from (16) and the final compensation voltage reference by transforming this compensation voltage reference in $\alpha \beta 0$ co-ordinates into the compensation voltage reference of three-phase co-ordinates.

$$
\mathrm{v}_{\mathrm{C}(\mathrm{a}, \mathrm{b}, \mathrm{c})}^{*}=[\mathrm{T}]^{-1}\left[\begin{array}{c}
\mathrm{v}_{\mathrm{C} \alpha}^{*} \\
\mathrm{v}_{\mathrm{C} \beta}^{*} \\
\mathrm{v}_{\mathrm{C} 0}^{*}
\end{array}\right]=\left[\begin{array}{c}
\mathrm{v}_{\mathrm{Ca}}^{*} \\
\mathrm{v}_{\mathrm{Cb}}^{*} \\
\mathrm{v}_{\mathrm{Cc}}^{*}
\end{array}\right]
$$




\section{SERIES SHUNT ACTIVE POWER FILTER (UPQC)}

As the name suggests, the series-shunt active filter is a combination of series active filter and shunt active filter. The topology is shown in Fig.11. The shunt-active filter is located at the load side and can be used to compensate for the load harmonics. On the other hand, the series portion is at the source side and can act as a harmonic blocking filter. This topology is called as Unified Power Quality Conditioner (UPQC). The series portion compensates for supply voltage harmonics and voltage unbalances, acts as a harmonic blocking filter and damps power system oscillations. The shunt portion compensates load current harmonics, reactive power and load current unbalances. In addition, it regulates the dc link capacitor voltage. The power supplied or absorbed by the shunt portion is the power required by the series compensator and the power required to cover losses. $[5,6,7,8]$

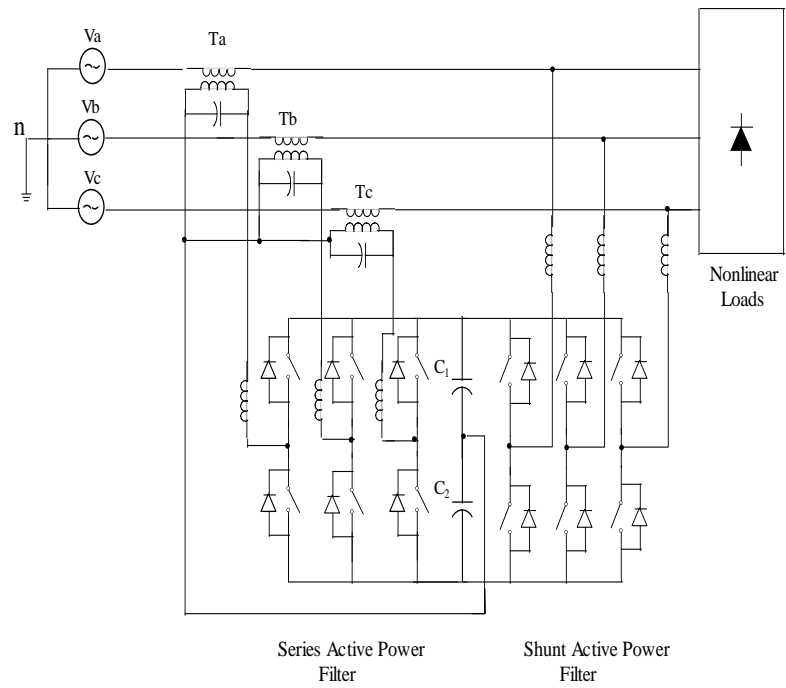

Fig.11 Unified power quality conditioner topology

\subsection{UPQC Operating Principle}

Distorted voltages in a 3-phase system may contain negative phase sequence, zero phase sequence as well as harmonic components. The voltage of phase "a" can be expressed as in general.

$\left.\mathrm{v}_{\mathrm{a}}=\mathrm{v}_{\mathrm{lpa}_{\mathrm{pa}}}+\mathrm{v}_{1 \mathrm{na}}+\mathrm{v}_{1 \mathrm{oa}}+\sum \mathrm{V}_{\mathrm{kaSin}} \operatorname{sint}+\theta_{\mathrm{ka}}\right)$

Where, $\mathrm{v}_{1 \mathrm{pa}}$ is the fundamental frequency's positive sequence component while $\mathrm{v}_{1 \mathrm{na}}$ and $\mathrm{v}_{\text {loa }}$ is the negative and zero sequence components. The last term of equation (1), $\sum \mathrm{V}_{\text {kasin }}\left(\mathrm{kwt}+\theta_{\mathrm{ka}}\right)$ represents the harmonics in the voltage. In order for the voltage at the load terminal to be perfectly sinusoidal and balanced, the output voltages of the series active filter should be:

$$
\mathrm{v}_{\mathrm{ah}}=\mathrm{v}_{\mathrm{lna}}+\mathrm{v}_{\mathrm{loa}}+\sum \mathrm{V}_{\mathrm{kaSin}}\left(\mathrm{kwt}+\theta_{\mathrm{ka}}\right)
$$

It will be shown how the series active filter can be designed to operate as a controlled voltage source whose output voltage would be automatically controlled according to equation (2).

The shunt active filter performs the following functions:

a) To provide compensation of the load harmonic currents to reduce voltage distortions.

b) To provide load reactive power demand.

c) To maintain the DC-link voltage to a desired level.

To perform the first two functions, the shunt active filter acts as a controlled current source and its output current should include harmonic, reactive and negative phase sequence components in order to compensate these quantities in the load current. In other words, if the load current of phase "a" is expressed as:

$$
\begin{aligned}
& \mathrm{i}_{\mathrm{aL}}=\mathrm{I}_{1 \mathrm{pm}} \cos \left(\omega \mathrm{t}-\theta_{1}\right)+\mathrm{I}_{\mathrm{aLn}}+\sum \mathrm{I}_{\mathrm{aLk}} \\
& \quad=\mathrm{I}_{1 \mathrm{pm}} \cos \omega \mathrm{t} \cos \theta_{1}+\mathrm{I}_{1 \mathrm{pm}} \sin \omega \mathrm{t} \sin \theta_{1}+\mathrm{I}_{\mathrm{aLn}}+\sum \mathrm{I}_{\mathrm{aLk}}
\end{aligned}
$$

It is clear that the current output of the shunt active filter should be: 
$\mathrm{i}_{\mathrm{ah}}=\mathrm{I}_{1 \mathrm{pm}} \sin \omega \mathrm{t} \sin \theta_{1}+\mathrm{I}_{\mathrm{aLn}}+\sum \mathrm{I}_{\mathrm{aLk}}$

Hence, the current from the source terminal will be:

$$
\mathrm{i}_{\mathrm{as}}=\mathrm{i}_{\mathrm{aL}}-\mathrm{i}_{\mathrm{ah}}=\mathrm{I}_{1 \mathrm{pm}} \cos \omega \mathrm{t} \cos \theta_{1}
$$

This is a perfect, harmonic-free sinusoid and has the same phase angle as the phase "a" voltage at the load terminal. The power factor is unity. It means that the reactive power of load is not provided by the source.

\section{CONCLUSIONS}

The mathematical analysis of operation of Shunt APF, Series APF and the UPQC can be used for effectively improving the power quality of an electrical power system. The Shunt APF has been used for compensating the source current harmonics. The Series APF has been used for compensating the load voltage harmonics. Whereas, the UPQC which has been used for compensating the source current and the load voltage harmonics simultaneously. Hence, the UPQC can be used for improving the power quality effectively.

\section{REFERENCES}

[1] Bhim Singh, Kamal Al Haddad and Ambrish Chandra, A Review of Active Filters for Power Quality Improvement, IEEE Trans on Industrial Electronics, Vol.46, No.5, Oct. 1999, pp. 960-970.

[2] S. K. Jain, P. Agrawal and H. O. Gupta, Fuzzy Logic controlled shunt active power filter for power quality improvement, IEE proceedings in Electrical Power Applications, Vol. 149, No.5, Sept. 2002.

[3] G.- Myoung Lee, Dong- Choon Lee, Jul-Ki Seok; "Control of Series Active Power Filters Compensating for Source Voltage Unbalance and Current Harmonics"; IEEE Transactions on Industrial Electronics, Vol. 51, No. 1, Feb. 2004, pp. 132-139.

[4] Jun Li, Hui Yan, Guoqing Tang, Ping Jiang, Cuimei Bo; "Simulation Study of the Series Active Power Filter Based on Nonlinear Immune Control Theory"; IEEE International Conference on Electric Utility Deregulation, Restructuring and Power Technologies (DRPT2004) April 2004, pp.758-762.

[5] V. Khadkikar, P. Agarwal, A. Chandra, A.O. Barry and T.D. Nguyen; "A Simple New Control Technique For Unified Power Quality Conditioner (UPQC)"; 11th International Conference on Harmonics and Quality of Power-2004, pp. 289-293.

[6] M. Vilathgamuwa, Y H Zhang., and S.S.Choi; "Modeling, Analysis and Control of Unified Power Quality Conditioner"; $8^{\text {th }}$ International Conference on Harmonics and Quality of Power ICHQP '98, by IEEE/PES and NTUA, Oct. I4-16, 1998, pp. 1035-1040.

[7] Hideaki Fujita, Member, IEEE and Hirofumi Akagi, Fellow, IEEE, "The Unified Power Quality Conditioner: The Integration of Series and Shunt Active Filters", IEEE Transaction on power electronics. Vol.13. No 2, March 1998, pp. 494-501.

[8] Yunping Chen, Xiaoming Zha*Jin Wang, Huijin Liu, Jianjun Sun and Honghai Tang "Unified Power Quality Conditioner (UPQC): The Theory, Modeling and Application” an IEEE paper-2000.

[9] Y.Sato, T.Kawase, M.Akiyama, and T.Kataoka, A control strategy for general - purpose active filters based on voltage detection, IEEE Trans. Ind. Appl., vol. 36, no.5, pp.1405-1412, Sep / Oct.2000

[10] Donghua Chen; Shaojun Xie; "Review of the control strategies applied to active power filters"; Electric Utility Deregulation, Restructuring and Power Technologies, 2004. (DRPT 2004). Proceedings of the 2004 IEEE International Conference on, Vol.2, 5-8 April 2004, pp.666 - 670.

[11] PENG, F.Z., AKAGI, H., and NABAE, A,: 'A study of active power filters using quad series voltage sourcc PWM convertcrs for harmonic compensation', IEEE Trans.Power Electron, 1990. 5, (I). pp. 915.

\section{BIOGRAPHIES}

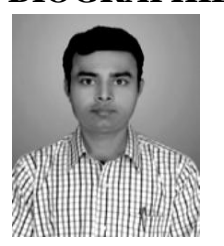

Vikash Anand is pursuing the PhD Degree with specialization of "Electrical Power Systems" in Electrical Engineering department at the National Institute Of Technology, Patna and received his M.Tech. Degree from Madan Mohan Malaviya Technical University, Gorakhpur (India) in the session of 2010-12. His research interest includes Power System's Quality Improvement.

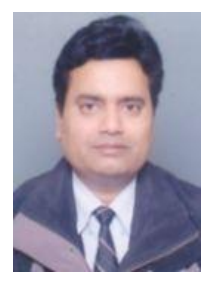

S. K. Srivastava received his B.Tech, M.Tech and PhD Degrees from MMM Engineering College Gorakhpur (India), IIT Delhi (India) and UP Technical University Lucknow (India) in the year 1986, 1993 and 2008 respectively. Presently, He is Associate Professor in the Department of Electrical Engineering at the Madan Mohan Malaviya Technical University Gorakhpur (India). His research interests include Power System Operation and Control, FACTS Deregulations, Fuzzy Logic and Neural Networks application in Power System Problems. 